\title{
INTERNATIONAL UNION OF PURE AND APPLIED CHEMISTRY
}

\section{COMMISSION ON GEOCHEMISTRY}

\begin{abstract}
HE Commission on Geochemistry of the International Union of Pure and Applied Chemistry held a meoting in Munich during August 26-27, during the twentieth Conference of the Union. Attending the meeting were the following members of the Commission: Prof. T. F. W. Barth (president), Dr. F. M. Vokes (acting secretary), Prof. C. Burri, Prof. C. W. Correns, Prof. S. I. Tomkeieff, Prof. L. R. Wager, Prof. F. E. Wickman and three observers of the Commission : Prof. A. P. Vinogradov, Prof. K. Sugawara and Prof. E. Ingerson.

The Commission discussed at length its future objects and aims, particularly with regard to the work of its sub-committees. The chairmen of the three existing sub-committees reported on their activities; these comprise the subcommittee on abstracting, translation and information; the subcornmittee on the chemistry of the oceans and the sub-committee on rock analyses. It was decided to broaden the scope and work of the Commission by forming sub-committees on "the organic compounds in the crust of the Earth" and "the beginning of the biosphere".

It was also considered highly desirable that some form of code should be compiled which could be used to indicate the exact analytical methods which had been employed in mineral and rock analyses reported in publications. It was decided to seek the co-operation of the Sections of Inorganic and Analytical Chemistry of the Union to further this end. The question of education and training for geochemistry was also discussed at some length. In particular, it was agreed that the education committee of the Geochemistry Society should be encouraged to produce a definitive report on this subject as a basis for further discussion.
\end{abstract}

The subject of future symposia on geochemistry came in for a considerable amount of discussion. It was decided to offer the Commission's co-operation in respect of the proposed symposium of the International Union of Geodesy and Geophysies to be held in Helsinki in July 1960, and that of the Geochemical Society to be held in Copenhagen in August 1960. For the Copenhagen symposium it was suggested that the Commission should be responsible for organizing a section of the geochemistry of sedimentary carbonate rocks.

Prof. A. P. Vinogradov of the Vernadsky Institute of Moscow gave the members present a short summary of the current geochemical work being carried out at the Institute. $\mathrm{He}$ also mentioned that discussions were taking place regarding the formation of a Russian geochemical society which ho hoped would in time be able fully to co-operate with similar bodies outside Russia. Prof. K. Sugawara also gave a short account of the position and activities of the Japanese Geochemical Society.

Election of Members. In order to replace those members due to retire at the end of the present year, the following were elected members of the Commission: Prof. L. H. Ahrens, Prof. E. Ingerson, Prof. K. Sugawara and Prof. A. P. Vinogradov. The officers elected for the session beginning 1960 were: President, Prof. C. W. Correns (Göttingen); Vice-President, Prof. A. P. Vinogradov (Moscow); and Secretary, Prof. E. Ingerson (Austin, Texas). In addition, it was decided to invite seven new observers to serve with the Commission. The president-elect, Prof. Correns, proposed a vote of thanks to the retiring president, Prof. Barth, for his work for the Commission during his term of office and this was carried with acclamation.

\section{SCIENCE AND PHILOSOPHY}

\begin{abstract}
$\mathrm{T}$ HE fourth annual conference of the British Society for the Philosophy of Science was held during September 25-27 at Newnham College, Cambridge, and was attended by about eighty members and guests. Dr. M, B. Hesse was conference secretary.

Four symposia were held: "Scientific Research and the Philosophy of Science", "Biology and Physics", "Classification, Concept-formation and Language", and "Knowing and Being".

At the first session, with Dr. J. O. Wisdom in the chair, it was argued whether 'philosophy of science' can be held to refer to any activity not properly subsumed under 'scientific research', and, if it can, whether that activity is relevant to research. Prof. H. Dingle mentioned various questions of value and purpose, as well as of method, papers on which were unlikely to be accepted for publication in journals concerned with particular sciences. Prof. H. C. Longuet-Higgins, on the other hand, argued that, of the product of philosophers of science, part was science, part was philosophy, and the remainder was
\end{abstract}

of no use to man or scientist. This aroused some consternation, as members consulted their own credentials and invoked those of others, but in due course a consensus emerged that scientists have to think critically about their thinking, and the comparative study of modes of scientific thought may help them to do so.

In the second session, Prof. J. H. Woodger described an abstractive hierarchy of terms characterized by a one-many relation, and its use as a con. ceptual framework in biology. With some hierarchies of cells, every cell is a distinct life ; with others, only the first cell in each hierarchy, elaboration occurring on subsequent levels. Morphology was the study of the arrangement and differentiation of parts; physiology was the study of the existential dependence of parts. Genetics was concerned with the process in which the first member of a hierarchy results from the conjunction of two members of other hierarchies. Dr. E. M. Hutten set alongside this framework the sequence exhibited by radioactive 
decay : each new atom produced was similarly timeextended, stemmed from a parent atom, and consisted of existentially dependent parts, but it was not dependent on its environment analogously to a cell. In elementary-particle theory, explanation might amount to little more than classification, or an enumeration of possibilities, and might have little more predictive power than comparable biological models with their over-determination and multiplecausation. The chairman, Prof. C. F. A. Pantin, referred to the occurrence, in biology, of morphological models that can be interpreted at more than one level in an organizational hierarchy. In discussion it was suggested that the predictive power of a theory might not always be manifest at the time of its original formulation; it might have to await development of deduction. There was much interest in the relative importance of the past history of an entity in biology and in physics : historical existential dependence appears to be a function of complexity.

In the third session, with Mr. G. Buchdahl in the chair, Miss M. Masterman and Mr. R. M. Needham presented the strategy, and some of the tactics, of a method of analysing language by assimilating it to a library classification system in which concepts are arranged on a finite lattice ordered by a single, weak, 'concordance' (inclusion) relation. They further suggested that the formation of scientific concepts is a development of language according to this model. There was some discussion as to whether the method is a technology for mechanical translation, or a science, or a philosophy of language, and it was suggested that it could be viewed as a scientific model of language, containing the partly uninterpreted concept 'inclusion', and capable of being tested by experiments on translation and on analogyfinding.

In the fourth session, under the chairmanship of of Dr. W. H. Thorpe, Prof. M. Polanyi presented a way of talking about the primary process of knowing by perception, the pre-articulate act of knowing, which partakes of the uniqueness of the individual percipient, the unspecifiable personal knowledge from which any specifiable, potentially public, knowledge is derived by a process of abstraction. Complex entities were commonly perceived and recognized as wholes before particulars had been identified; the process of discovery, in fact, might be regarded as an alternation of analysis, recognizing particulars, and integration, recognizing the relations of parts to the whole. Prof. R. B. Braithwaite suggested that too narrow a view might be taken of specifiability, and that some levels of subjective experience, however vague, could be conveyed by language-for example, 'Oblomov' conveys the experience of laziness; beyond that, he differed from Prof. Polanyi in his use of the term 'knowledge' for what was unspecifiable. In the subsequent discussion there was some reluctance to focus on this rather undemocratic mode of tacit awareness, and a preference for talking about what can be made public, with the implication that the progressive refinement of scientific language tends to eliminate the unspecifiable.

In conclusion, it is perhaps worth directing attention to the unusualness of a scientific conference at which speakers are not armed with specified and verifiable data but attend primarily to make as explicit as possible how they think, and to receive criticism of the process thereby revealed, especially from those who are not working in the same field. The coherence of this universe of discourse was illustrated by the frequency of reference from one discussion to another, the esprit d'escalier from one session often finding its outlet in a later one ; its range, by the frequency of spontaneous quotation, not only from Shakespeare and Wordsworth but also from Swinburne (and early Swinburne, at that).
G. E. DENYER

\section{FOURTEENTH ANNUAL CALORIMETRY CONFERENCE}

\begin{abstract}
$\mathrm{T}$ HE fourteenth annual Calorimetry Conference, held at Yale University in the Sterling Chemistry Laboratory during September 10-12, was attended by more than one hundred scientists from the United States, Canada and Europe. Under the chairmanship of Dr. David White (Ohio State University) thirty papers were read and discussed. These included: heat capacity measurements at temperatures as low as $0.1^{\circ} \mathrm{K}$. and as high as $1,400^{\circ} \mathrm{K}$.; precision reaction and bomb calorimetry; solution calorimetry; and determinations of stored energy in solids.

Most of the papers were concerned with recent developments in calorimetry. However, as calorimetric techniques are extended to more extreme conditions, the problems that led to the founding of the Conference remain under new guises. The need for better temperature measuring devices was emphasized in seven papers that reported on research at temperatures below $11^{\circ} \mathrm{K}$. No device comparable to the platinum resistance thermometer, now in general use for measurements above $11^{\circ} \mathrm{K}$., is yet available for the very low temperatures at which some of the most important calorimetric
\end{abstract}

research is now being done. However, the reports on a device that may extend precision thermometry to at least $1^{\circ} \mathrm{K}$., namely, the germanium resistance thermometer developed in the Bell Telephone Laboratories, were received enthusiastically. Twelve of these thermometers had been provided for a calorimetry conference test programme involving eleven different laboratories. Three papers at the Yale conference described the first results of the investigations, which were so promising that the Conference plans to seek a manufacturer of additional units for a more extensive testing programme.

Special addresses were given by Profs. George S. Parks (Stanford University) and Lars Onsager (Yale University). At the annual banquet, Parks delivered the Hugh M. Huffman Memorial Lecture, "Some Remarks on the Thermodynamic Properties of Organic Compounds". Parks and one of his first graduate students, the late Dr. Huffman, started the first systematic calorimetric studies of organic compounds at Stanford more than thirty years ago. Enlivening his remarks with many personal anecdotes, Parks traced the history of thermodynamic research on organic substances and the role improvement 